\title{
Community's willingness to pay for a school-based chemotherapy programme to control morbidity due to schistosomiasis and soil-transmitted helminthiasis in children in rural Tanzania
}

\author{
N.J.S. LWAMBO* ${ }^{*}$, J.E. SIZA \& G.C. MWENDA ${ }^{\dagger}$ \\ National Institute for Medical Research, Mwanza Research Centre, P O Box 1462, Mwanza, Tanzania
}

\begin{abstract}
A cross-sectional questionnaire survey was conducted on a random sample of 523 households having at least one child attending primary school in 3 villages in Buchosa Division, Sengerema District, Tanzania. The aim was to determine the community's willingness to pay (WTP) for a school-based chemotherapy programme to control morbidity due to schistosomiasis and soil-transmitted helminthiasis (STH) in schoolchildren and identify socio-economic and cultural factors influencing community's WTP. Results showed that households WTP for a school-based chemotherapy programme varied from Tanzanian Shillings (TShs.) 0-20,000 (US\$ 0-25) per child per year. The community's WTP (median of households WTP) was TSh. 1,000 ( US\$ 1.25). The community was also willing to pay extra TSh.100 (US \$ 0.125 ) per year to cover for the cost of schoolchildren whose parents were unable to pay or who could pay less than the community's WTP. Age of household head and number of schoolchildren in a household had a negative effect on the household's willingness to pay. Households with children in expensive schools had high willingness to pay for the intervention package to control worms in their children. This was also observed in households keeping animals (cattle, goats, sheep, chiken, ducks) and those who cultivated a number of cash crops.
\end{abstract}

Key words: schistosomiasis, control, willingness to pay, Tanzania

\section{Introduction}

Public health services in Tanzania are in transition from post independence egalitarian 'free' health services under socialist policy to 'cost sharing/user fees' in the tune of structural adjustment programme. Under the socialist philosophy health services in the country were provided free and considered to be an integral part of the overall social and economic development plans. The present economic constraint in Tanzania, like in many other developing countries, hinders the provision of free social services such as health care. Tanzania government, therefore, is rolling out different financing mechanisms (e.g. user fees, community health funds, insurance schemes) of providing social services, such as health care. The option being pursued is aimed at limiting direct government involvement in operation and/or the introduction of user fees in financing health services.

The focus of health sector reforms in Africa has been on 'cost sharing' in which patients are required to pay user fees for health care service. In Tanzania cost sharing scheme has been introduced in curative health care services at health centre and hospital levels, for both in- and outpatients. Prior to the introduction of cost sharing in health care delivery, willingness to pay (WTP) studies were conducted and showed that Tanzanians were willing to pay for health care provided they were assured of good service (Abel-Smith \& Rawal, 1992, Walvaren, 1996).

Cost sharing need not be limited to the curative health care services; it could be extended to disease prevention and control services. User fees may be applied in the control of endemic diseases such as schistosomiasis and soil-transmitted helminthiasis $(\mathrm{STH})$, which cause morbidity in many people in Tanzania, especially school-age children (Lwambo et al., 1996; Partnership for Child Development, 2001).

School delivery of interventions to control morbidity due to schistosomiasis and STH in school-age children has been found to be the most cost-effective strategy (Bundy 1990, Guyatt et al., 1994, 2001; Partnership for Child Development, 1998). The objectives of this study were to determine (i) community's WTP for school-based chemotherapy programme to control morbidity due to schistosomiasis and STH in schoolchildren; and

\footnotetext{
* Correspondence: N.J.S. Lwambo; Email: 1wambon@hotmail.co.uk

$\dagger$ Deceased
} 
(ii) socio-economic and cultural factors influencing community's WTP in Sengerema district in northwestern Tanzania.

\section{Material and Methods}

\section{Study area}

The study was conducted in three villages, namey Nyakaliro, Bukokwa and Luchili in Buchosa Division, Sengerema District, Tanzania $\left(2^{\circ}, 07^{\prime} \mathrm{S}\right.$, $\left.32^{\circ}, 30^{\prime} \mathrm{E}\right)$ in $1998-1999$. This area is reported by Lwambo et al. (1996) to have a prevalence of Schistosoma mansoni of 70-92\%, S. haematobium of $40-56 \%$ and hookworm of $35-67 \%$. The study area borders with Lake Victoria to the North. Occupation of the people is subsistence farming, fishing and cattle rearing.

\section{Questionnaire survey}

The study utilized a contingent valuation technique to determine community's willingnes to pay for a school-based chemotherapy programme by questionnaire survey. The questionnaire was constructed in English and translated in Kiswahili (the country's national language) then pre-tested in Kamanga village (Katunguru Division) on 100 household heads. After pretesting the questionnaire was improved and the results of pre-testing provided an estimate of the community's WTP in the area which saved as a starting point for the bidding game. Iterative bidding is sensitive to initial price offered. Normally, in order to avoid starting point bias, cards with different prices written, are presented to respondents from which they can choose the amount they are willing to pay. However, this could not be done because most of the respondents in the study area were illiterate.

A sample of 523 heads of household ( 174 in each of the 3 villages studied) with at least one child attending primary school were randomly drawn from a list of parents. Iterative bidding game was used to elicit the WTP of individual household heads and the median WTP of the individual household heads provided the community's WTP. The influence of socio-economic and cultural factors on community's WTP was also determined by questionnaire.

\section{Hypothetical scenario}

The scenario presented to the respondents was as follows: 'The National Institute for Medical Research (NIMR) among its duties is to conduct health/medical research and interventions against schistosomiasis and soil transmitted helminthiasis in the country. The Institute has conducted research in Sengerema District recently and revealed that a high proportion of school aged children between the age of 6-15 years are highily infected by these worms. The worms are of different types, and the signs and symptoms of disease are haematuria, anaemia and extended abdomen. These worms make your children ill, also in the long-term, affect the general health of your children causing stunting and low school performance. In terms of heavy hookworm infection, anaemia occurs and if severe your child may die. The Institute plans to establish a long-term school-based intervention programme whereby all schoolchildren will be treated with Praziquantel tablets yearly and six monthly with Albendazole tablets and micronutrient supplementation (iron tablets). This treatment programme will eliminate the worms and your child's health will improve'.

Two questions were posed to respondents: (i)If the package was only available to your child if you paid some amount of Tanzanian shillings (TShs X), would you pay the amount each year for your child to participate?; (ii) We believe that at this cost (TShs $\mathrm{X}$ ), not all parents could afford to pay for the package. How much extra would you be willing to pay to ensure that all children in your school would benefit from the package so that those unable to pay can still be covered?

Respondents were asked if they would be willing to pay TShs 800 (US\$ 1) for intervention package with reponses coded as YES or NO. If the answer was 'YES' then the interviewer would proceed to raise the amount by increments of TShs 200 until the maximum value the respondent would be willing to pay. If the answer was 'NO' then the interviewer would proceed to decrease the amount by TShs 200 until an amount is reached which the respondent is willing to pay or until reaches zero. Where a respondent was not willing to pay for the intervention programme the interviewer enquired for the reasons. Likewise, on the second question to determine extra WTP to assist households which are 
not willing to pay or would pay lower than the community's WTP so that their children can also be covered, the starting point of the bidding game was TShs 400 (US \$ 0.5). The bidding was done in the same fashion as in the first question with incements or decrements of TShs 100 (US\$ 0.125).

\section{Socio-economic and cultural factors}

Social and cultural factors investigated likely to affect WTP of households included gender, age, marital status, education, number of wives, number of children, number of dependants, occupation and village of domicile. Indirect economic factors were condition of house (type of wall and roof), possessions (eg cattle, canoe, fishing nets), size of business and type of employment (if any). The direct economic factors investigated were amount of salary, business income and other monetary sources of income such as sales of crops, animals or any commodity.

\section{Results}

Individual household WTP in the study area varied from TShs 0 to 20,000 (US\$ 0-25) per child per year. Table 1 shows that only $27(5.2 \%)$ of households had WTP of TSh. 0 while 370 (70.7 \%) of households had WTP of TShs. $\geq 1,000$, that is, equal or greater than the median WTP. The community's WTP (median of individual household WTP) was TShs. 1,000 (US\$ 1.25).

Table 1: Household willingness to pay for a school-based chemotherapy programme

\begin{tabular}{ll}
\hline $\begin{array}{l}\text { Willingness to pay } \\
\text { (in TShs) }\end{array}$ & $\begin{array}{l}\text { No. (\%) of } \\
\text { households }\end{array}$ \\
\hline 0 & $27(5.2)$ \\
$1-999$ & $126(24.1)$ \\
$\geq 1,000$ & $370(70.7)$ \\
Median WTP $=1,000$ & $523(100.0)$ \\
\hline
\end{tabular}

Exchange rate: US\$1.0 $=$ TShs 800.0

Of the 27 households who were not willing to pay anything (WTP equal to TShs 0 ), 21 (78\%) had male household heads and only $6(20 \%)$ had female household heads. Age of household head appearred to affect WTP because in those 27 households, 20 (74\%) had elderly household heads (age $\geq 50$ years).
Most of the respondents who were not willing to pay, $21(78 \%)$ said it was the government's responsibility to finance the programme because they were paying taxes, while only $6(22 \%)$ cited poverty as the main reason.

Table 2 shows the distribution of household willingness to pay extra to ensure that all children in their school would benefit from the intervention package so that those unable to pay can still be covered. A total of 224 (42.8\%) were unwilling to pay anything extra to assist those not able to pay for their own children to be included in the chemotherapy programme. The community was willing to pay extra TShs 100 (median WTP extra) (US\$ 0.125) per year to cover for the cost of schoolchildren whose parents were unable to pay or who could pay less than the community's WTP

Table 2: Household WTP extra to ensure that all children in a school would benefit from the intervention package

\begin{tabular}{ll}
\hline $\begin{array}{l}\text { Willingness to pay extra } \\
\text { (TShs) }\end{array}$ & $\begin{array}{l}\text { No. (\%) of } \\
\text { households }\end{array}$ \\
\hline 0 & $224(42.8)$ \\
$1-300$ & $217(41.5)$ \\
$301-600$ & $64(12.3)$ \\
$\geq 600$ & $18(3.4)$ \\
Median WTP $=100$ & $523(100)$ \\
\hline
\end{tabular}

Exchange rate: US $\$ 1.0=$ TShs 800.0

Table 3 shows results of multivarite ordered logit analysis of explanatory factors (socio-economic and cultural) of household WTP. A group of five factors were found to be signifficantly associated with household WTP. Households were willing to pay less as the age of household head increased and as the number of schoolchildren in a household grew bigger. Households which paid bigger amounts as school fees had higher WTP for the intervention package to control worms in their children, perhaps indicating also a higher ability to pay. Those households keeping animals (cattle, goats, sheep, chiken, ducks) and those who cultivated a number of cash crops were associated with a higher WTP. All other factors studied were not significantly associated with WTP of respondents. 
Table 3: Coefficeints obtained in a multivariete ordered logit analysis

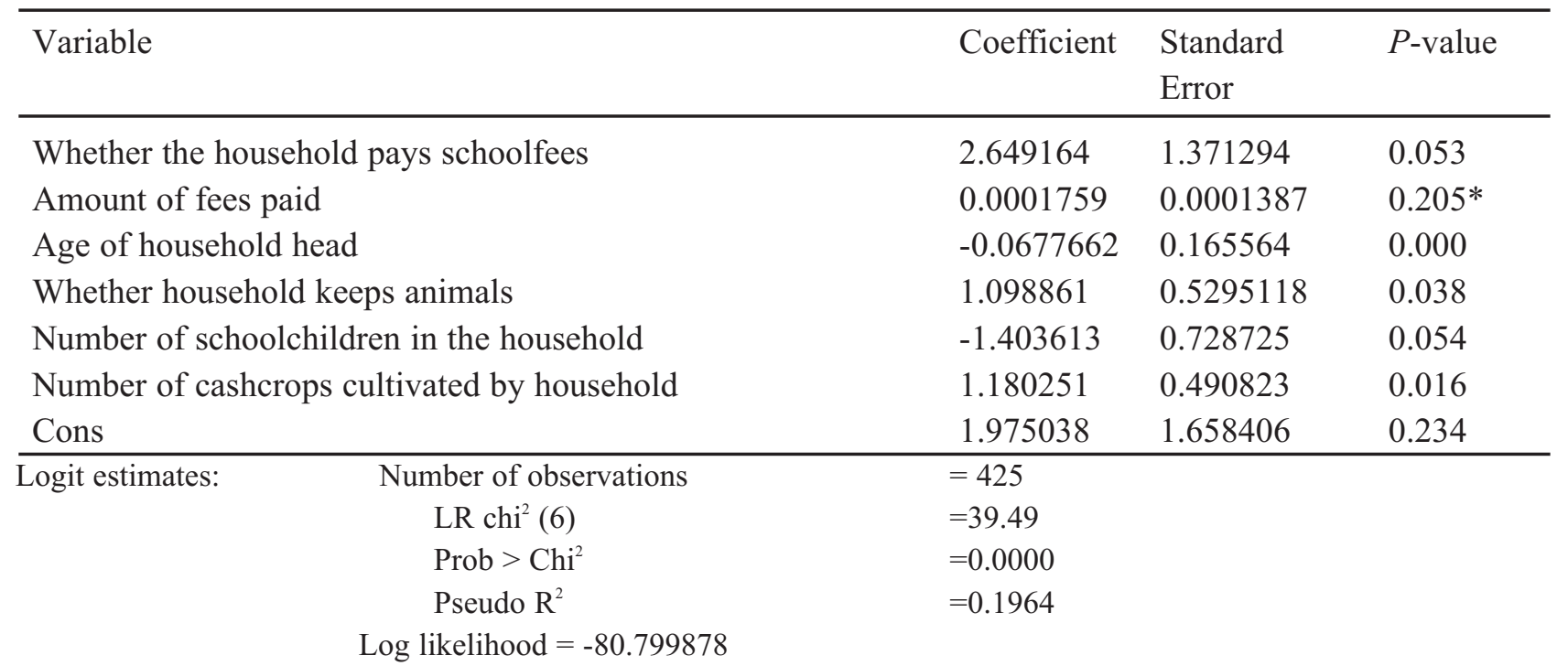

\section{Discussion}

The results suggest that the community perceived a benefit in terms of better health for their children by participating in the anticipated (hypothetical) chemotherapy programme to control morbidity due to schistosomiasis and STH and were willing to use resources for it. Age of household head and the number of schoolchildren in the household were negatively associated with willingness to pay. Programme managers, therefore, when planning cost-recovery schemes should make considerations for children whose household heads are elderly and who come from households with many schoolchildren, because their parents may have lower willingness to pay. This may limit coverage of an intervention programme. Paying of school-fees and the amount of fees actually paid by a household were positively correlated with household willingness to pay, perhaps indicating also ability to pay. In Tanzania, schoolchildren of the elderly and from poor households are normally exempted from paying school-fees. Other indicators of wealth associated with higher willingness to pay were keeping of domestic animals and cultivation of a number of cash crops. Cotton, pineapples and oranges are cultivated as cash crops and are a direct source of money. Households with domestic animals such as cattle, goats, sheep, chicken or ducks could sale an animal for cash when a need arises and were willing to use these resources to pay for better health for their children.

Bundy (1990) suggested that school-based delivery of interventions against schistosomiasis and STH in school-age children of poor endemic countries is a most cost-effective strategy. This approach has been investigated in Tanzania and elsewhere and shown to be most cost-effective (Partnership for Child Development, 1998, UKUMTA 1998).

The cost per child of a school-based chemotherapy programme to control morbidity due to schistosomiasis and STH in Tanzania has been estimated at US \$ 0.23 for Albendazole and US \$ 0.79 for Praziquantel or US \$ 1.02 per child treated with both drugs (Partnership for Child Development, 1998; Guyatt et al., 2001). This covered the price of the drug and delivery costs including those of distribution, training and prior screening for $S$ haematobium. The cost could have been even lower, if mass chemotherapy was given. Therefore, the community's WTP of US\$ 1.25 covers more than the cost of a school-based chemotherapy programme to control schistosomiasis and STH using Praziquantel and Albendazole in rural Tanzania. In this case, the community's WTP of US\$ 1.25 per child per year for the programme may cover, not only, the financial cost of treating a child yearly with both drugs (Praziquantel and Albendazole), but also, may contribute to children unable to pay or those paying on a scale lower than the community's WTP.

These findings are relevant to African countries planning national programmes for the control of schistosomiasis and STH depending on 
philanthropy to cover programme expenses. Such sources of funds have a time limit and the issue of cost recovery will, most likely, arise as it takes years for control efforts to suceed. Therefore, the need for community financing of intervention programmes cannot be over-emphasized in oder to sustain them. The findings of this study indicates that the community is willing to pay for a cost-effective intervention package to control morbidity due to helminths infections in children.

\section{Acknowledgements}

The author acknowledges the assistance of Ms Pelepetua Bulemela and Ms Claudia Mathias with fieldwork and Mr R Isingo for statistical analysis. This study received financial support from World Bank/UNDP/WHO Special programme for Research and Training in Tropical Diseases

\section{Reference}

Abel-Smith, B. \& Rawal, P. (1992) Can the poor afford 'free' health service? A case study of Tanzania. Health Policy \& Planing 7, 329-341.

Bundy, D.A.P. (1990) New initiatives in the control of helminths. Transactions of the Royal Society of Tropical Medicine and Hygiene 84, 467468.

Guyatt, H.L, Evans, D., Lengeler, C. \& Tanner, M. (1994) Controlling schistosomiasis: the costeffectiveness of alternative delivery strategies. Health Policy \& Planning 9, 385-395.

Guyatt, H.L., Brooker, S., Kihamia C.M., Hall, A. \& Bundy, D.A.P. (2001) Evaluation of efficacy of school-based antihelminthic treatments against anaemia in children in the United Republic of
Tanzania. Bulletin of the World Health Organization 79, 695-703.

Lwambo, N.JS., Gabone, R.M., Temu, M.M., Siza, J.E., Mashauri, F. \& Mwanga, J.R. (1996) Epidemiology of scistosomiasis and geohelminthiasis in two rural communities in Sengerema ditrict, Mwanza, Tanzania. 15th Annual Report of the National Institute for Medical Research, Tanzania, pp. 59-67.

Lwambo, N.J.S., Siza, J.E., Brooker, S., Bundy, D.A.P., Guyatt, H. (1999) Patterns of concurrent hookworm infection and schistosomiasis in schoolchildren in Tanzania. Transactions for the Royal Society of Tropical Medicine and Hygiene 93, 497-502.

Lwambo, N.J.S., Broker, S., Siza, J.E, Bundy D.A.P. \& Guyatt, H. (2000) Age patterns in stunting and anaemia in African schoolchildren: a cross sectional study in Tanzania. European Journal of Clinical Nutrition 54, 36-40.

Partnership for Child Development (1998) Cost of a schoolbased drug treatment in Tanzania. Health Policy and Planning 13, 384-396.

Partnership for Child Development (2001) Anaemia in schoolchildren in eight countries in Africa and Asia. Public Health Nutrition 4, 749 - 756.

UKUMTA (1998) An Evaluation of Efficacy of School-based Antihelminthic Treatments on the Health of Schoolchildren in Tanga Region in Tanzania. UKUMTA. Dar-es-Salaam, Tanzania.

Walvaren, G. (1996) Willingness to pay for district hospital services in rural Tanzania. Health Policy \& Planing 11, 428-437. 